\title{
Biodefense cost and consequence
}

A fter the intentional release of anthrax into the United States mail system in October 2001, and in the midst of rumors of weapons of mass destruction in Iraq, the US government substantially ramped up its biodefense research. In light of the huge growth in this area, the question that arises is this: What are the overall costs and benefits of such an enormous program for the US population and the world?

Last February, at a Department of Defense Pest Management Workshop, Lieutenant Colonel George W. Korch Jr. outlined the plans for a new National Biodefense Analysis and Countermeasure Center (NBACC) to be built at Fort Detrick, Maryland (http:// www.cbwtransparency.org/archive/nbacc. pdf). This prompted a commentary that voiced concerns that, in carrying out some of the NBACC directives, the US might be crossing the line between a biological research program that is defensive and one that is offensive (1), thereby breaking the Biological Weapons Convention (BWC).

Milton Leitenberg, one of the authors of the commentary and a research scholar at the School of Public Policy at the University of Maryland, told the JCI, "The crucial word [in the Biological Weapons Convention] is in the one line which says you cannot develop biological agents or toxins. The problem is, there is no definition of the word 'develop.' No formal definition. No international definition."

The complete sentence in the BWC is this: "Under the terms of the convention, the parties undertake not to develop, produce, stockpile, or acquire biological agents or toxins 'of types or in quantities that have no justification for prophylactic, protective, and other peaceful purposes' as well as weapons and means of delivery."

The main areas of concern in the plans for the NBACC, according to Leitenberg and colleagues, are several bulleted points on page 16 of Korch's presentation that highlight specific task areas for technical threat assessment: acquire, grow, modify, store, stabilize, package, and disperse. Leitenberg notes that several of these task areas cut close to types of studies that the National Academy of Sciences has highlighted as “experiments of concern” (see Table 1) (2).

Leitenberg said, "I don't know what goes into these words: acquire, grow, modify, store, stabilize, package, disperse. What do

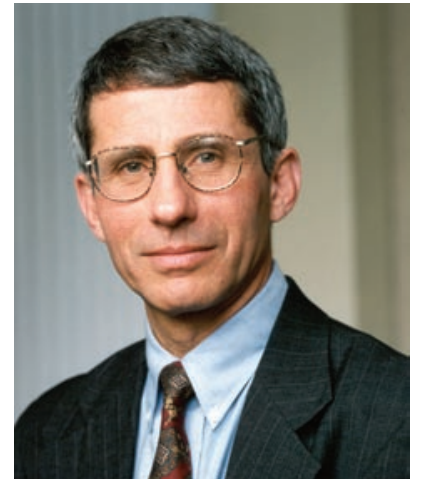

Anthony Fauci. "It's a concern that is understandable, but the facts do not justify that concern at all."

we want to do in 'package' and 'disperse' that we haven't already done? What do we want to do in 'stabilize' that we didn't already do in our offensive program?" The US, like many other countries, had offensive biological weapons programs prior to the BWC treaty and had already carried out a great deal of research in this area.

The other aspect Leitenberg finds especially troubling in the NBACC plans relates to the modeling and simulation of disease transmissions. While in their commentary, Leitenberg and colleagues were careful to note that there is only the possibility that this work may be perceived as threatening the BWC, Leitenberg admitted, "My personal assessment is that when you are doing high-fidelity modeling and simulation and computational modeling of feasibility methods and scale of production, you've crossed the line."

Leitenberg believes that in doing such work, the US may in fact be a driving force in instigating a world-wide increase in biological agent and toxin research, which can ultimately only be harmful to the world population as a whole.

Anthony Fauci, the Director of the National Institute of Allergy and Infectious Diseases, believes that the concerns about the current and proposed activities for biodefense are overblown. "There is a common, perhaps understandable, but certainly not justifiable, concern that when you try to develop countermeasures [such as] diagnostics, therapeutics and vaccines, that you are therefore, in fact, making weapons of mass destruction," Fauci said to the JCI. While people may liken the biodefense work in the
US to the biological weapons research done in the Soviet Union in the 1970s, Fauci feels the comparison is off base. The Soviets, he said, "were making [anthrax] in industrial quantities to be able to use it as weapons, and then people were trained to make that," he explained. "What we do is we train people to make countermeasures; we don't train people to make weapons ... It is done under the most highly regulated conditions." Fauci likens the difference between US work on bioweapons and that of the Soviet Union to apples and oranges, adding that "if you look into the kinds of precautions that are taken and what the ultimate goal is, [US bioweapons work serves] to enhance the fundamental research of how we can protect ourselves as opposed to making a new weapon.”

When asked for details about the plans for the NBACC, Colonel Gerald Parker, Director of the Department of Homeland Security's Office of Science-Based Threat Analysis, told the JCI, "There are two major thrust areas for the programs that will be executed at this facility. The first one is a bioforensics analysis program. The other major thrust is a threat characterization program."

For the forensics effort, the NBACC will play a key role in coordinating and directing other laboratories nationwide in forensic analysis of potential biological threats as well as developing and performing new analyses.

"The threat-characterization program is all related to establishing a rigorous and scientifically based risk-analysis process so that we can better understand the threat - whether it is a current threat - and also to anticipate what future threats may be." Parker said. "It really comes down to being the foundation of where broader biodefense research

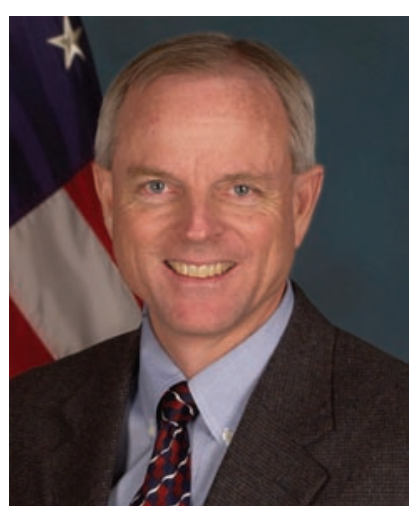

Gerald Parker. "Our program is defense." 


\section{Table 1}

Areas of concern in biological agent and toxin research as defined by the National Academy of Sciences (2).

\author{
Would proceeding with the experiment ... \\ Render a vaccine to a pathogen ineffective? \\ Confer antibiotic resistance to a pathogen so as to decrease the effectiveness of a countermeasure? \\ Increase the virulence of a pathogen? \\ Increase the transmissibility of a pathogen? \\ Increase the host range/tropism of a pathogen? \\ Enable evasion of diagnostic/detection capabilities? \\ Demonstrate weaponization of a pathogen?
}

programs need to be directed, so that we are making sure, as the US government, that we are working on the right countermeasures . .. So awareness of the threat is fundamental to understanding exactly where the broader biodefense efforts need to be directed."

When asked what research will be carried out under threat characterization, Parker responded, "This comes down to establishing a rigorous risk analysis. So some of this will be an analytical component, trying to better quantitate what a threat would constitute, to better quantitate what are our vulnerabilities to a proposed threat or a potential threat, and, of course, that begins to indicate a net assessment. The net assessment would indicate what countermeasures need to have priority effort and funding placed on them, whether the Department of Homeland Security is working on them, whether [the Department of] Health and Human Services is working on them, whether the Department of Defense is, whether the USDA is, and so forth."

Prompted for more specifics, Parker added, "There are information gaps in our understanding about the threats and even our vulnerability [to] the threats. So the laboratory component of the threat characterization will be focused on addressing high-priority information gaps in either understanding the threat or our vulnerabilities.”

When asked specifically about the term "modify" that was in Korch's task list, Parker stated emphatically, "We will not be intentionally enhancing pathogenicity of organisms to do what-if type studies." However, he added that "if there is information either in the classified or open literature, and it is validated information, that indicates that somebody may have [enhanced pathogenicity], and that we believe indicates that we might have a vulnerability in our defensive posture, we may have to in fact evaluate the technical feasibility and the vulnerability of our countermeasures." He also indicated that he does not anticipate that this will be one of their major concerns.

While one could fashion justification for enhancing the pathogenicity of organisms, some raise additional concerns about doing such research at all, such as the inherent dangers created simply by having such organisms around. One of these people is Peter Gilligan, a professor at the University of North Carolina Medical School, who has been involved in many facets of US biodefense strategies, including helping to devise the standard operating procedures for the sentinel labs that are part of the US National Laboratory Response Network (LRN). (These guidelines are available at the American Microbiology Society website, http://www.asm.org/Policy/ index.asp?bid=667; details about the LRN are available at the CDC website, http:// www.bt.cdc.gov/lrn/factsheet.asp.)

Gilligan pointed out, "We know that the anthrax strain that was recovered here in the United States [from the October 2001 incident] was a common strain, that it had not been enhanced in any way, yet it still killed almost $50 \%$ of the people who got inhalation anthrax. So it is a pretty doggone virulent organism. So, bottom line,

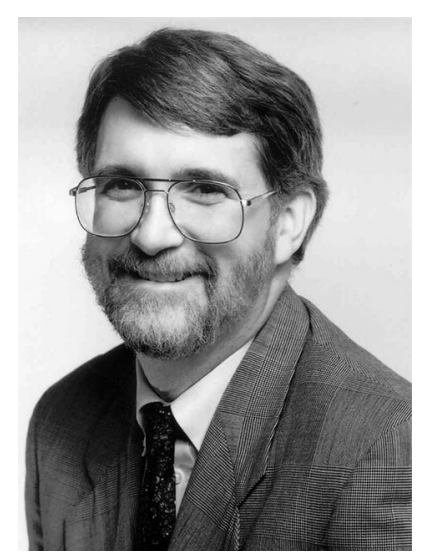

Peter Gilligan. "I'm not as optimistic as others that the hundreds of millions of dollars being spent is going to greatly enhance our security."
I'm really uncomfortable with the idea of enhancing virulence or putting antibioticresistance genes in organisms.”

He also indicated that having enhanced strains around is inherently more dangerous due to the potential for someone with ill intent acquiring them. "Every bit of information that I know of right now," he noted, "points to ... the anthrax that was used here in the United States [as] a strain that was once in a governmental lab."

Intentional release aside, there is also human error. A case in point is the accidental release of anthrax from a Soviet military facility into the community of Sverdlovsk in 1979, which killed more than 60 civilians. And just recently, on June 11, there was a report that researchers at the Children's Hospital Oakland Research Institute were exposed to anthrax when scientists at the Southern Research Institute in Frederick, Maryland, accidentally sent live anthrax instead of killed germs.

Gilligan also argued that, although biodefense research is important, a great deal of this work should be considered more carefully and openly in larger forums, not just because of potential dangers, but also because the financial and ethical costs versus the overall health benefits are not entirely clear, given the rarity of infection from most of the organisms being studied.

"There are going to be positives that are going to come out of this, but there is also a lot of money being spent, unfortunately, that could probably be spent in a lot better ways. We're spending ... hundreds of millions of dollars - maybe even into the billions - to develop new medicines and new vaccines for biodefense when we have proven medications that [could be given] to pregnant women in Africa and other countries [to prevent AIDS] in so many children.”

While making sure our defensive posture is sound is an important and essential task, several people feel it would behoove the community to carefully weigh the price we may pay from the standpoint of the potential of increasing biological weapons research worldwide, the inherent dangers in such research, and the financial burden relative to the overall health benefits for these generally rare diseases.

\section{Laurie Goodman}

1. Leitenberg, M., Leonard, J., and Spertzel, R. 2004. Biodefense crossing the line. Politics Life Sciences. 22:1-2.

2. National Research Council. 2004. Conclusions and recommendations: the criteria for review. In Biotechnology Research in an Age of Terrorism. National Academies Press. Washington, D.C., USA. 113-115. 